\title{
FORMAÇÃO DE EDUCADORES NUMA PERSPECTIVA DE CONSTRUÇÃO DO SABER - CONTRIBUTOS DA ABORDAGEM BIOGRÁFICA
}

Carmen de Jesus Dores Cavaco *

\begin{abstract}
RESUMO: O texto tem o objectivo de analisar uma prática de formaçáo de educadores em que se recorreu à abordagem biográfica, procurando compreender a especificidade desta abordagem formativa e o seu contributo no desenvolvimento profissional dos atores envolvidos. A análise enquadra-se numa investigação qualitativa, que recorreu a dois tipos de dados empíricos - a explicitação de uma prática de formação e as narrativas biográficas elaboradas pelos educadores. A formação é entendida como um processo amplo, que ocorre em todos os espaços e tempos da vida, operando-se um distanciamento crítico face à forma escolar. A investigação revela a importância da formação ser entendida como um processo de apropriaçáo individual e colectiva do vivido, o que confirma a pertinência da formação de educadores se basear na análise das suas experiências, através da superação da forma escolar, com o entendimento que sujeitos são autores na produçáo de conhecimento.
\end{abstract}

Palavras-chave: Formação. Educadores. Histórias de vida. Experiência. Saberes.

* Universidade de Lisboa, Instituto de Educação, Lisboa, Portugal. E-mail de contato: carmen@ie.ul.pt. 


\title{
Teacher education under a knowledge construction perspective - contributions of the biographical approach
}

\begin{abstract}
This article aims to analyze the practice of teacher training. During this analysis we used a biographical approach, seeking to understand the specificity of this formative approach and how it contributes to the professional development of the actors involved. For this qualitative research, two types of empirical data were used - the specification of a practical training and the biographical narratives, elaborated by the educators. Teacher education is herein understood as a broad process, which occurs in all spaces and phases of the educator's life, operating at a critical distance from the schooling model. This investigation reveals the importance of understanding teacher education as an individual and collective process of appropriation of what has been experienced, confirming the relevance of a teacher training model based on the analysis of their experiences, overcoming the schooling model, and understanding that the subjects are actors in the production of knowledge.
\end{abstract}

Keywords: Training. Educators. Biographical approach. Experience. Knowledge.

\section{INTRODUÇÃO}

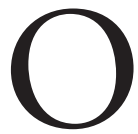

texto tem o objectivo de analisar uma prática de formação de educadores em que se recorreu à abordagem biográfica. Através da análise desta prática de formação pretendemos problematizar a especificidade da abordagem biográfica quando usada na formação e o seu contributo no desenvolvimento profissional dos atores envolvidos. $\mathrm{O}$ recurso à abordagem biográfica permite-nos equacionar a formação na perspectiva do "formar-se", operando um distanciamento crítico face ao modelo escolar e procurando contribuir para a construção de uma outra epistemologia da formação. (DOMINICÉ, 1988, 1991; JOSSO, 1988; NÓVOA, 1988) 
O recurso à abordagem biográfica no dispositivo orientado para a formaçáo de educadores de jovens e adultos resultou de três pressupostos: o primeiro assenta-se na ideia que um profissional com intervenção directa na formação atribui outro sentido à sua actividade profissional se ele próprio reflectir sobre o modo como se formou; o segundo baseia-se no princípio que nas situaçóes educativas, é a pessoa em formação que construi o seu conhecimento; o terceiro consiste na ideia que tem de haver uma adesão voluntária para a realização da narrativa biográfica, porque só desse modo o sujeito atribui sentido e se implica no processo. Estes pressupostos fundamentam-se na valorização da pessoa em formação e na sua capacidade de autonomia, partindo de uma inspiração humanista e de uma concepção emancipatória do conhecimento. (FREIRE, 1972) O uso da abordagem biográfica é "inseparável da reabilitação progressiva do sujeito e do actor”. (JOSSO, 2002, p. 13)

A análise enquadra-se numa investigação qualitativa, em que se recorreu a dois tipos de dados empíricos - a explicitação de uma prática de formação e as narrativas biográficas elaboradas pelos educadores. A tradição da investigação qualitativa caracteriza-se por apresentar "[...] um carácter iterativo e retroactivo, marcado pela simultaneidade da recolha de dados, análise e elaboração das questôes de pesquisa [...]." (DESLAURIERS; KÉRISIT, 1997, p. 99) Nesta perspectiva, o investigador assume um papel de bricoleur criativo que tem uma margem de autonomia considerável para (re)definir e construir em permanência o objecto de estudo, o qual depende dos dados recolhidos, da metodologia, do enquadramento teórico, mas também do campo disciplinar em que se enquadra. Estes elementos intimamente associados à construção do objecto de estudo são influenciados por questóes epistemológicas, teórico-metodológicas e pela experiência de vida e valores do investigador. Neste caso, a análise centra-se num dispositivo de formação no qual o investigador assumiu, primeiramente, o papel de formador e, posteriormente, através do recurso à explicitaçáo da prática e à análise das narrativas dos educadores foi possível investigar o processo em que esteve implicado. Esta situação resulta do facto da abordagem biográfica apresentar a possibilidade de articular duas dimensôes - a formação e a investigação. (DOMINICÉ, 1988; JOSSO; 1989, 2002; NÓVOA, 1988) 
O texto está organizado em três partes, a primeira foca-se na metodologia da investigação, a segunda centra-se em questôes teóricas e metodológicas da abordagem biográfica em formação, e a terceira na análise de uma experiência de formação de educadores, inspirada na abordagem biográfica.

\section{METODOLOGIA - DA FORMAÇÃO À INVESTIGAÇÃO}

A análise que se apresenta resultou de um processo de formação de educadores de jovens adultos que decorreu nos últimos anos, no Mestrado de Ciências da Educação da Universidade de Lisboa. A partir dos pressupostos anteriormente identificados, a equipa responsável pelo curso propôs aos participantes a realização de uma narrativa biográfica centrada no seu percurso profissional. Ao longo de um ano lectivo, a elaboração da narrativa biográfica era articulada com elementos metodológicos referentes às especificidades da abordagem biográfica, com aspectos conceptuais do campo científico das Ciências da Educação e, mais especificamente, da formação de adultos, assim como um acompanhamento dos educadores em pequenos grupos e em tutorias individuais. A implementação deste mestrado durante vários anos contribuiu para a formação de mais de uma centena de educadores de jovens e adultos, implicados num processo em que foram sujeitos da sua própria formação.

A problematização que se apresenta resultou da análise da prática profissional de um dos docentes envolvidos no processo. Neste caso, é imperioso reconhecer que o processo de investigação está fortemente articulado com as trajectórias de vida, os valores, as crenças e os quadros de referência que transportamos, reconhecendo-se que estes "[...] são a prova íntima do nosso conhecimento, sem o qual as nossas investigaçóes [...] constituiriam um emaranhado de diligências absurdas sem fio nem pavio [...]". (SOUSA SANTOS, 2000, p. 80) Esta investigação resultou da combinação entre a experiência e o raciocínio, constituindo um processo lógico e sistemático (RODRIGUES-LOPES, 2005), processo que, no plano epistemológico, foi marcado essencialmente pelos pressupostos inerentes à perspectiva fenomenológica. A perspectiva fenomenológica, como o próprio nome indica, centra-se no estudo dos fenómenos, par- 
tindo do pressuposto que estes são construçôes que resultam da acção dos actores sociais; entende-se que o "[...] mundo social não nos é dado, como postulam os positivistas, mas é constantemente construído pelos actores sociais [...]". (LAPERRIÈRE, 1997, p. 311) Neste caso, a construção dos factos resulta de uma atribuição de sentido à realidade, que é mediada pelas nossas referências teóricas, esquemas de pensamento, experiências, interacçóes com os outros e com o ambiente. Trata-se de uma abordagem aberta que, ao defender o carácter construído dos fenómenos sociais, reconhece o seu carácter contingencial e a relação dialéctica sujeito/objecto.

\section{ABORDAGEM BIOGRÁFICA E A FORMAÇÃO}

O uso da abordagem biográfica na formação, iniciado nos anos 1980, no âmbito das Ciências da Educação, suporta-se numa ideia de ruptura com a forma escolar e na necessidade de se construir uma nova epistemologia da formação. Quando a narrativa de vida se centra numa reflexão sobre o percurso de formação do sujeito, este tem de reflectir sobre o percurso de vida, as várias fases e os acontecimentos. Embora a reflexão incida numa vertente retrospectiva, esta mobiliza os vários tempos de vida - o passado, o presente e o futuro. A reflexão é orientada através da rememoração do percurso vivido, todavia, é conduzida pela situação que vive no presente, mas também pelo que já projecta no seu futuro (projectos, sonhos, expectativas). Neste caso, o trabalho centrado na história de vida, como destaca António Nóvoa (2002), mais do que o passado permite reflectir e pensar o futuro.

Os sujeitos que elaboram uma narrativa biográfica centrada na análise do percurso de formação compreendem, através da sua própria experiência, que a educação e a formação são processos muito amplos e difusos que se confundem com a socialização e com a história de vida. Neste caso, o sujeito pode incorporar que o processo educativo, para além, da educação formal, compreende também as modalidades de educação não formal e informal, sendo a educação formal "apenas a face visível do iceberg”. (CANÁRIO, 1999) A elaboração da narrativa permite, ao sujeito envolvido, perceber que o processo de formação resulta 
sempre da apropriaçáo do vivido, o que justifica a preponderância da autoformação. (PINEAU, 1988) As narrativas biográficas colocam em evidência o sentido da Teoria Tripolar da Formação de Gaston Pineau (1988), ao destacar a importância das pessoas com as quais nos cruzamos, nos vários contextos, ao longo da vida, o que constitui a heteroformação; a relevância dos contextos na realização de uma grande diversidade de aprendizagens, a designada ecoformação; e o carácter essencial da apropriação do vivido por parte do sujeito implicado - a autoformação.

As narrativas biográficas permitem compreender a complexidade e especificidade do percurso de vida e de formação de cada sujeito. Através das narrativas biográficas torna-se notório que a aprendizagem ocorre com muita frequência, em espaços e tempos diversos, quando não é programada. O que corrobora a perspectiva de Ivan Illich (1971) quando este defende que a aprendizagem é um processo natural no ser humano e que não consente manipulaçôes. $\mathrm{O}$ carácter incorporado e complexo do processo de formação justificam a dificuldade inerente à construção da narrativa biográfica. $\mathrm{O}$ trabalho individual e colectivo, realizado pelos educadores, ao longo do mestrado, possibilita-lhes uma compreensão ampla do processo de educação e formação, enquanto prática social, marcada pela singularidade de cada percurso e, em simultâneo, a percepção do carácter invisível e náo consciente deste processo. Os sujeitos envolvidos na elaboração da narrativa biográfica apercebem-se que o processo de formação não se deixa captar facilmente. (DOMINICÉ, 2001)

O recurso à abordagem biográfica junto de educadores de jovens e adultos visa contribuir para uma problematização e questionamento dos seus quadros conceptuais sobre a formação e as suas opçóes metodológicas na prática profissional. Procura-se que estes consigam construir um pensamento crítico face ao modelo escolar a partir da análise e reflexão sobre a sua própria experiência e seu processo de formaçáo. A construção da narrativa biográfica coloca os educadores numa posição de actores, que são construtores do seu próprio saber. Esta perspectiva enquadra-se no pensamento de Paulo Freire (1997) quando defende que “[...] ensinar não é transferir conhecimento, mas criar possibilidades para a sua produção ou construção [...]” (p. 25). 
A formação pós-graduada baseada na abordagem biográfica foi organizada em quatro etapas: na primeira exploraram-se elementos históricos e epistemológicos sobre o uso de histórias de vida em formação e investigação, no âmbito das Ciências da Educação; na segunda, apresentou-se um roteiro estruturante para conduzir a reflexão e a escrita da narrativa e pediu-se aos educadores para apresentarem um relato oral, em grupos de dois elementos, a partir da selecçẫo de um momento muito significativo do percurso profissional; a terceira fase centrou-se na escrita da narrativa num trabalho autónomo, que era articulado com o relato oral, em sala de aula, em pequenos grupos, de modo a haver partilha e reflexão em torno de percursos de vida, de formas de organização e de escrita da narrativa, assim como de dificuldades; a quarta fase incidiu na análise teórica da narrativa e de uma reflexão sobre a metodologia, as dificuldades e as aprendizagens realizadas no decurso do trabalho. Ao longo da elaboração da narrativa, durante um semestre, e na fase de aprofundamento e aperfeiçoamento, que se prolongava mais um semestre, os educadores contavam com tutorias individuais para acompanhamento da elaboração da narrativa biográfica.

A narrativa biográfica constrói-se através da historicidade, individual e colectiva. Para elaborar a narrativa o sujeito precisa dar uma consistência temporal específica ao seu percurso, aos acontecimentos, aos momentos mais significativos na sua formação. A enunciação oral ajuda na identificação e na selecção dos momentos-chave, na rememoração, na (re)elaboração da experiência e na explicitação do percurso. Durante a enunciação oral o sujeito começa a aperceber-se da especificidade do seu percurso e da sua formação, mas na partilha com o outro também descobre as proximidades e os traços comuns dos processos de formação. A passagem para a narrativa escrita exige algum tempo para se operar o distanciamento face ao vivido e a selecção de uma estratégia que permita organizar a narrativa e assegurar o seu fio condutor. A escrita da narrativa é marcada por dúvidas, bloqueios e angústias, o que é particularmente evidente no caso de pessoas que não têm o hábito de escrever sobre si. $\mathrm{O}$ autor da narrativa confronta-se com o actor que realizou o percurso, o que exige momentos de grande implicação na reflexão, de (re)elaboração da experiência e de escrita, com momentos de distanciamento face à narrativa escrita. A alternância entre estes dois movimentos de implicação-distanciamento permite aprofundar a reflexão e avançar 
na (re)elaboração da experiência, o que é muito importante para dar consistência à narrativa. A narrativa biográfica centrada no processo de formação é um processo que está sempre inacabado, porque a formação é um movimento que é necessário saber captar durante o percurso. (DOMINICÉ, 2001)

Analisar a narrativa biográfica é um trabalho exigente para os sujeitos implicados, nesta fase é importante assegurar a articulação entre o vivido, o percurso de formação e conhecimento científico sobre a formação. Durante as várias fases o sujeito assume diferentes papéis e transitar de um estatuto para outro torna-se o mais difícil - a vida e o processo de formação foram vividos pelo actor social, a escrita da narrativa biográfica foi assegurada pelo autor e na fase da análise, convoca-se uma terceira figura, o investigador. Assumir as três figuras numa mesma pessoa torna-se uma tarefa exigente. Adoptar o papel de investigador do seu próprio processo de formação é normalmente tido como o mais difícil porque é necessário um afastamento e conceptualização a partir do vivido. Todavia, a análise teórica centrada no processo de formação é indispensável para que o recurso à abordagem biográfica possa constituir uma metodologia centrada na apropriação do vivido e na autoformação. Para que uma história de vida "[...] se torne um instrumento de conhecimento - por isso de formação - para o actor, é necessário que ele seja implicado na análise da sua própria narrativa [...]”. (PINEAU, 2000, p. 167-168)

\section{FORMAÇÃO CENTRADA NO "FORMAR-SE" - A PERSPECTIVA DOS SUJEITOS}

Neste ponto pretendemos analisar a formação centrada no "formar-se" a partir da perspectiva dos sujeitos envolvidos no dispositivo de formação. Por uma questão de economia de textos, a análise incide apenas na sua visão sobre o uso da abordagem biográfica em formação. Os comentários que se apresentaram foram retirados de narrativas biográficas realizadas por educadores de jovens e adultos do mestrado anteriormente identificado. Optou-se pelo recurso a nomes fictícios como forma de assegurar o anonimato. 
As questóes da temporalidade estão presentes em todas as narrativas, uma vez que se trata de um factor inerente à abordagem biográfica que, como se destacou anteriormente, convoca a reflexão sobre o percurso vivido (o passado), a partir da situação em que se encontra (o presente) e tendo já como referências as perspectivas de futuro. Esta dimensão da temporalidade está presente quando a Beatriz afirma: "[...] acredito também que este exercício marca não só uma nova fase de vivência da minha profissão, como também me capacitou para novos desafios [...]". A presença do passado, do presente e do futuro surge também no discurso da Joana quando afirma: "A construção de toda a narrativa biográfica trouxe a oportunidade de criticar lucidamente o meu percurso profissional e perspetivar a construção de novas experiências profissionais, à luz do que foi analisado e refletido [...]”. A reflexão sobre as experiências de vida são analisadas e reequacionadas à luz do presente, procurando-se reforçar padróes de comportamento e acção tidos como correctos e ajustados, por outro lado, percebe-se a importância de proceder a alteraçóes no futuro e de se pensar em novos projectos.

Para além dessa dimensão temporal anteriormente identificada, por vezes, as narrativas colocam em destaque a importância de um tempo de reflexão, que é tido como ruptura, paragem e suspensão das rotinas diárias. Esse tempo necessário à reflexão é essencial para se criarem as condiçóes propícias à elaboração da narrativa. Normalmente, a experiência não se verbaliza e não temos por hábito reservar momentos específicos para sistematizar e (re)elaborar de um modo consciente a experiência. Esta exigência do trabalho biográfico é considerada como um grande contributo da metodologia, como se percebe na narrativa da Lia, "Nem sempre parei para reflectir [ao longo dos oito últimos anos]. Pelo menos náo o fiz com muita facilidade ou espontaneamente. [...] $O$ enquadramento no qual foi desenvolvido este mestrado, mais do que permitiu, obrigou-me a parar. Parar para pensar e repensar-me [...]”. Este tempo de pausa, de atenção concentrada no vivido é um tempo de introspecção, que dá origem às descobertas anteriormente mencionadas. $\mathrm{O}$ tempo é necessário para a rememoração, para a reflexão e para a criação de um certo distanciamento face ao vivido. Os estudos realizados nas neurociências (DAMÁSIO, 2010) alertam-nos que o cérebro precisa encontrar mecanismos capazes de coordenar a evocação das memórias, devido ao elevado número de objectos presentes nas nossas biografias, 
por outro lado, muito do vivido encontra-se na mente náo consciente e o acesso a essa informação não é imediato, pelo contrário carece de tempo para ficar acessível, por último, sabe-se que a reconstrução da experiência ocorre, em grande medida, através de processos não conscientes.

A análise das narrativas autobiográficas permite compreender a importância que os sujeitos atribuem à reflexividade, destacando que se trata de um ganho conquistado com a elaboração do registo biográfico. A reflexividade é um elemento intrínseco e condição necessária para a elaboração da narrativa biográfica, o que conduz o sujeito a um conjunto de "descobertas" e leituras sobre o seu percurso, a sua aprendizagem, as suas opçóes, os seus erros, as suas conquistas e vitórias, os seus projectos de vida e a sua existência. As transcriçôes que se apresentam corroboram a importância da reflexividade, o seu contributo para a apropriação do vivido e para o planeamento do futuro.

A reflexividade enquanto mecanismo indutor de descobertas sobre o percurso realizado está presente quando a Joana menciona que a narrativa biográfica lhe exigiu "[...] um tempo de reflexão, que por fim culminou na descoberta do verdadeiro sentido das experiências na minha vida profissional e pessoal [...]". A Joana reforça o contributo da elaboração da narrativa na apropriação do vivido, o que conduz à compreensão da importância da experiência de vida na formaçáo, em todos os domínios da existência - familiar, social, profissional, escolar. Ideia reforçada pela Sónia que ao fazer o balanço sobre o significado da elaboração da narrativa biográfica, usa uma citação de Carl Gustav Jung "Quem olha para fora, sonha. Quem olha para dentro, acorda.”. A narrativa biográfica mobiliza o sujeito numa reflexão ampla sobre o seu percurso, o que justifica a presença permanente da dimensão identitária. O autor da narrativa confronta-se a si próprio, enquanto actor do percurso vivido, com a necessidade de identificação de momentos significativos, a partir dos quais explicita o vivido e as aprendizagens realizadas. António Damásio (2010) considera que o eu autobiográfico tem uma vida dupla - uma dimensão explícita que constitui a mente consciente e uma dimensão latente, a mente não consciente. A narrativa biográfica pelo recurso à reflexividade mobiliza estas duas dimensóes, propiciando uma reformulação da memória e o acesso a elementos que até ao momento podiam fazer parte da mente náo consciente. Durante a elaboração da narrativa 
biográfica os acontecimentos e as situaçóes "adquirem um novo peso emocional". (DAMÁSIO, 2010, p. 264)

As descobertas que o sujeito faz são centradas em si próprio e podem estar relacionadas com saberes e capacidades desconhecidas ou desvalorizadas pelo próprio, com contextos e pessoas muito significativas no percurso de vida e na sua formação, com as suas estratégias e modos de aprendizagem, e com a sua dimensáo existencial. A Beatriz conseguiu perceber, através da elaboração da narrativa biográfica, que o seu percurso de vida foi muito centrado na imagem que procurava transmitir aos outros, numa tentativa de obter reconhecimento, como é visível nas suas palavras "Senti durante muito tempo que tudo o que fiz e o que vivi assumia um propósito maior: ter um emprego, ter um bom emprego, ter conforto, ter prestígio, ser reconhecida [...]".

A elaboração da narrativa biográfica permitiu-lhe tomar consciência que a sua acção era, predominantemente, orientada numa lógica de exterioridade (JOSSO, 1988), o que a estimulou a procurar agir mais de acordo com a sua interioridade "Hoje procuro outros sentidos, menos dependente dos outros e mais reais para mim. Procuro diariamente as coisas que me fazem sentir bem [...] e o presente exercício foi essencial para esse processo de descoberta [...]". A exterioridade/interioridade é uma dimensão que atravessa a nossa existência (JOSSO, 1988), todavia, nem sempre é inteligível para o sujeito. O sujeito, através da elaboração da narrativa, pode torná-la consciente e procurar alterar os seus padróes.

A interdependência dos vários domínios da vida e das múltiplas dimensóes da existência é identificada pelos formadores - actores e autores das narrativas, como se pode verificar nas palavras da Sónia "[...] explicar quem sou atualmente, como sou, como penso e ajo extravasa o percurso académico e profissional; há toda uma dimensão por detrás destas duas que, por vezes, subestimamos à força de querermos cientificar o nosso percurso [...]”. A Sónia tomou consciência que não é possível separar as várias dimensões da vida (pessoal, social, familiar, profissional), porque a sua estrutura existencial é marcada por todas, em simultâneo. Por isso destaca "[...] a minha forma de ser, os meus princípios e valores, a minha vivência, a minha experiência são as cores que iluminam a minha paleta e fazem com que eu seja esta e não outra pessoa e, consequentemente, esta formadora e não outra [...]". As palavras da Sónia confirmam que a 
elaboração de narrativas biográficas em formação conduzem o sujeito num "caminhar para si" (JOSSO, 2002, p. 42), através de um exercício sistematizado e consciente sobre o seu percurso de vida.

A narrativa biográfica coloca o autor na senda do seu processo de formação, como se verifica na afirmação da Joana "[...] permitiu-me encontrar e evidenciar as minhas estratégias enquanto aprendente. Assim, conheço as minhas resistências [...]”. A Sónia considera que aprendeu através da "observação e imitação seletiva dos outros e por tentativa-erro". Destaca também que a aprendizagem foi

[...] influenciada, condicionada, aguçada pela minha curiosidade inata, pela motivação implícita, pelos conhecimentos anteriores, pela quantidade de informação sentida como importante, pela diversidade das atividades, pela planificação e organização, pela cooperação que nasce da interaçáo e da ajuda mútua $[\ldots]$.

Embora reconheça a importância dos outros, ou seja, da heteroformação, ressalta que a aprendizagem só se concretiza com um grande investimento, esforço e vontade individual. Neste caso, reforça-se a ideia que está na base do recurso às narrativas biográficas na formação - a formação exige sempre um processo de apropriação individual (DOMINICÉ, 1988; JOSSO, 1988; NÓVOA, 1988), o que justifica o enfoque no "formar-se". A apropriação do processo de formação, das estratégias e mecanismos de aprendizagem, assim como a identificação de bloqueios à sua realização, conduzem estes profissionais a perceber a complexidade da sua actividade enquanto impulsionadores da aprendizagem de outros.

\section{CONCLUSÃO}

A abordagem biográfica é baseada na revalorização da experiência e, em simultâneo, os trabalhos inspirados nesta metodologia contribuem para fortalecer a importância da revalorização epistemológica da experiência, como se verifica nas narrativas. A revalorização epistemológica da experiência permite passar de um entendimento da 
formação centrada no "formar" para reconhecer a importância desta incidir no "formar-se", com toda a diversidade, complexidade e subtileza que lhe está inerente. Reconhecer o potencial formativo da experiência leva-nos a admitir que todas as pessoas têm capacidade de aprender, individual e colectivamente, e que por isso mesmo são o principal recurso nas situaçóes de formação. Os formadores envolvidos neste processo revelam uma tomada de consciência da importância do "formar-se" no seu percurso de formação, condição necessária para que possam adoptar outro entendimento sobre a formaçáo na sua prática profissional.

A elaboração da narrativa envolve um processo de (re)elaboração da experiência, o que permite a construção de um outro olhar sobre o vivido e, concomitantemente, promove e reforça a sua apropriação, o que constitui um processo de autoformação, tendo como referência a Teoria Tripolar da Formação, de Gaston Pineau (1988). O contributo da narrativa biográfica para a apropriaçáo do vivido e, desse modo, para o desencadear de um processo de formaçáo é um aspecto destacado nas narrativas, como se constata na afirmação de Joana "[...] a abordagem desenvolvida ao longo deste curso de Mestrado resultou num processo de autoformação enquanto educadora de adultos [...]". A apropriação do vivido desencadeia um processo de autoformação que conduz o sujeito a reequacionar o seu passado e o seu presente, para a partir daí projectar o futuro.

A narrativa biográfica permite, ao sujeito, uma reflexão aprofundada sobre a sua dimensão existencial, pois o percurso de vida e o processo de formação estão fortemente interligados com a sua existência enquanto pessoa. A questão da identidade "perpassa as narrativas" (JOSSO, 2002, p. 33), percebendo-se, através dos relatos, que há uma procura incessante de individuação. Os educadores envolvidos neste projecto de formação, orientado para o "formar-se", revelaram a importância do conhecimento de si próprios, o que passou, necessariamente, por uma análise atenta das suas posiçóes existenciais. Neste caso, como escreve Marie-Christine Josso (2000) "[...] o autoconhecimento poderá inaugurar a emergência de um eu mais consciente e perspicaz para orientar o futuro da sua realização e reexaminar, na sua caminhada, os pressupostos das suas opções [...]”, o que notório nos trechos das narrativas. Os educadores consideram que a narrativa biográfica permitiu a construção de 
um conhecimento sobre si próprios, através de várias "descobertas", que consideram determinante na sua acção futura enquanto profissionais e cidadãos.

\section{REFERÊNCIAS}

CANÁRIO, R. Educação de Adultos. Um campo e uma problemática. Lisboa: Educa, 1999.

DAMÁSIO, A. O livro da consciência. A construção do cérebro consciente. Maia: Círculo de Leitores, 2010.

DESLAURIERS, J.-P.; KERISIT, M. Le devis de recherche qualitative. In: POUPART, J. et al. La Recherche qualitative. Enjeux épistémologiques et méthodologiques. Montréal: Gaëtan Morin, p. 85-111, 1997.

DOMINICE, P. La contribution de l'approchebiographique à la connaissance de la formation. In: HOFSTETTER, R.; SCHNEUWLY, B. (Eds.). Le pari des sciences de l'éducation. Bruxelles: BoeckUniversité, p. 277-291, 2001.

. A biografia educativa: Instrumento de investigação para a educação de adultos. In: NÓVOA, A.; FINGER, M. (Orgs.). O método (auto)biográfico e a formação. Lisboa: Ministério da Saúde/Departamento de Recursos Humanos, p. 101-106, 1988.

FREIRE, P. Pedagogia da autonomia. Saberes necessários à prática educativa. São Paulo: Paz e Terra, 1997.

. Pedagogia do oprimido. Porto: Afrontamento, 1972.

ILLICH, I. Une société sans école. Paris: Éditions du Seuil, 1971.

JOSSO, M.-C. Experiências de vida e formação. Lisboa: Educa, 2002.

. Da formação do sujeito... ao sujeito da formação. In: NÓVOA, A.; FINGER, M. (Orgs.). O método (auto)biográfico e a formação. Lisboa: Ministério da Saúde/Departamento de Recursos Humanos, p. 35-50, 1988.

LAPERRIÈRE, A. La théorisation ancrée (groundedtheory): démarche analytique et comparaison avec d'autres approches apparentées. In: POUPART, J. et al. La Recherche qualitative. Enjeux épistémologiques et méthodologiques. Montréal: Gaëtan Morin, p. 309-340, 1997. 
NÓVOA, A. Prefácio. In: JOSSO, M.-C. Experiências de vida e formação. Lisboa: Educa, p. 7-12, 2002.

. A formação tem de passar por aqui: as histórias de vida no projecto PROSALUS. In: NÓVOA, A.; FINGER, M. (Orgs.). O método (auto)biográfico e a formação. Lisboa: Ministério da Saúde/Departamento de Recursos Humanos, p. 107-130, 1988.

PINEAU, G. Temporalités en formation. Vers de nouveaux synchroniseurs. Paris: Anthropos, 2000.

RODRIGUES-LOPES, A. Introdução à edição Portuguesa. In: TUCKMAN, B. Manual de Investigação em Educação. Lisboa: Fundação Calouste Gulbenkian, p. XV-XXVI, 2005.

SOUSA SANTOS, B. A crítica da razão indolente. Contra o desperdicio da experiência. Porto: Ediçôes Afrontamento, 2000.

Recebido em 06 de março de 2015.

Aprovado em 11 de maio de 2015.

DOI: $\underline{\text { http://dx.doi.org/10.1590/CC0101-32622015146876 }}$ 